\title{
A!
}

This is an electronic reprint of the original article.

This reprint may differ from the original in pagination and typographic detail.

Aaltonen, Kirsi; Ahola, Tuomas; Artto, Karlos

\section{Something old, something new}

Published in:

International Journal of Project Management

DOI:

10.1016/j.ijproman.2017.03.004

Published: 01/07/2017

Document Version

Peer reviewed version

Published under the following license:

CC BY-NC-ND

Please cite the original version:

Aaltonen, K., Ahola, T., \& Artto, K. (2017). Something old, something new: Path dependence and path creation during the early stage of a project. International Journal of Project Management, 35(5), 749-762.

https://doi.org/10.1016/j.ijproman.2017.03.004

This material is protected by copyright and other intellectual property rights, and duplication or sale of all or part of any of the repository collections is not permitted, except that material may be duplicated by you for your research use or educational purposes in electronic or print form. You must obtain permission for any other use. Electronic or print copies may not be offered, whether for sale or otherwise to anyone who is not an authorised user. 


\section{PAPER HIGHLIGHTS}

- The paper advances the understanding of path dependence and path creation during the early stage of multi-stakeholder projects.

- In the empirical study, we identify specific path dependence and path creation processes, which induce lock-ins and the creation of new directions for the project, respectively.

- Contrary to earlier research with an ahistorical view suggesting that abundant design options are available to stakeholders, the findings show that the project may have been locked to a pre-existing historical path already during its early stage.

- On the other hand, changes in the project's stakeholder network can trigger radical changes that redirect the project to a new development path.

- The research contributes to research on the management of the project's early stage by theorizing on project stakeholder management, and path dependence and path creation research. 


\title{
SOMETHING OLD, SOMETHING NEW: PATH DEPENDENCE AND PATH CREATION DURING THE EARLY STAGE OF A PROJECT
}

\begin{abstract}
Urban renewal projects involve several public and private stakeholders whose interaction during the project's early stage determine the scope of the project. Prior research has conveyed a somewhat ahistorical view of this early stage, based on the assumption that abundant design options are available to stakeholders. This study of a multi-stakeholder project, focused on the renewal of the commercial center of the historic garden city of Tapiola, seeks to increase understanding of processes of path dependence and path creation during the project's early stage. The findings show how a project and its stakeholders can be locked into a path that is affected by the stakeholders' shared history. The findings further reveal how external triggering events, emergent stakeholder dynamics, and active individual agency contribute to change in the project's goals, enabling breaking of the shared path and the gradual creation of a new path.

Keywords: early project stage; path dependence; path creation; multi-stakeholder project; urban renewal project; Tapiola garden city, project stakeholder management
\end{abstract}




\section{INTRODUCTION}

In a sense, this whole development project of Tapiola's center has been shadowed by the history of the world-famous Tapiola garden city and its architecture ... Many of the stakeholders -when evaluating and contributing to the plans initially-had the idyllic 1950's garden city picture of Tapiola as their frame of reference.

With these words, the project director from City of Espoo characterized the ongoing complex, multi-stakeholder urban renewal project to bring change to Tapiola district by establishing a vibrant commercial center with residential housing in the center of the district. Built in the postWorld War II era and located within the Helsinki metropolitan area in Finland, Tapiola is a heritage district, internationally recognized for its unique architecture and garden city character. In essence, the project director's words declare that history always matters, even in the process of creating something new. Multi-stakeholder projects are networks (DeFillippi and Sydow, 2016; Hellgren and Stjernberg, 1995), in which decision-making processes and behavioral patterns are conditioned by the prehistories, prior interactions of actors, and by the ever-changing stakeholder networks in which projects are embedded (Manning and Sydow, 2011).

In organization research, understanding how and why history matters in organizational life has come to be of central interest (Sydow et al., 2009). In particular, the concept of path dependence (David, 1985; Arthur, 1989), which has its origins in evolutionary economics, has gained prominence. The notion of path dependence asserts in general that our present and future choices are conditioned by decisions we have made in the past, and that these decisions create increasingly constrained processes that cannot easily be escaped (Vergne and Durand, 2010). On the other hand, the idea of path dependence has been criticized for its failure to take account of 
the role of human agency in the creation of new paths (Garud and Karnoe, 2001). To address this limitation, Garud and Karnoe (2001) advanced the contrasting perspective of path creation, suggesting that individuals, organizations, and fields may also break away and mindfully deviate from their expected paths. In particular, there have been calls for more research examining pathrelated processes in inter-organizational contexts such as multi-stakeholder projects (Hellström et al., 2013; Levering et al., 2013; Sydow et al., 2009). The concepts of path dependence and path creation offer a novel perspective from which to examine processes that occur during the dynamic early stage of project networks, as multiple stakeholders seek to establish a joint direction for the project. The organizational entity that we analyze here is the stakeholder network in one such project's early stage. During this time, multiple stakeholders together form a path for the network through their independent or coordinated actions and decisions, often by seeking to establish overall system-level goals, design solutions, scope and joint routines to enable them to work jointly toward this goal. In the later stages of the project, this may also involve changing this goal (Artto et al., 2016).

The study addresses the following research question: How are path dependence and path creation processes manifested during the early stage of a multi-stakeholder project? In particular, we investigate how these processes are associated with the formation of the path that the project takes and what kinds of role are played by multiple stakeholders in the processes of path dependence and creation. The aim here is to extend our knowledge of the sporadic process involving the multi-stakeholder network in either enforcing previously set goals or changing goals and actions, and ultimately defining new direction for the project and the network of organizations. 
The unit of observation in this empirical study was a multi-stakeholder urban renewal project of the commercial center of Tapiola district (hereafter referred to as "the Tapiola project"). In total, investments in the Tapiola project from different stakeholders amounted to 3.4 billion euros. The early stage of the project lasted for twelve years (2000-2012), during which time the project's network organization sought and continuously adjusted the goals, design and plans of the renewal project when defining and redefining the project's scope. This early stage was divided into three distinctive phases in our empirical analysis. Typically, the early stage of an urban renewal project may last significantly longer than actual implementation—perhaps even for several decades. Despite the importance of this long period, preceding more detailed design and implementation of the project, prior research offers limited theoretical understanding of how the project's path, particularly in terms of the joint goals, design solutions and scope, actually takes shape in this initial stage through the sporadic interactions and decision-making of the various stakeholders (Edkins et al., 2013; Morris, 2013).

The present study contributes in four ways to the literatures on management of the early project stage, project stakeholder management, and path dependence and path creation. First, the findings challenge previous accounts of the abundant availability of design options and choices in a project's early stage by showing how path dependence processes may already impose restrictions on multiple stakeholders' decision-making when the project commences. Second, the study enhances understanding of stakeholder network dynamics during a project's early stage by showing how changes in the stakeholder network structure can facilitate path creation processes that may radically change the project's scope. Third, through evidence of both path dependence and path creation during a project's early stage, the study characterizes goal formulation processes in multi-stakeholder projects as continuously evolving and affected by changes in the 
stakeholder constellation. Finally, the study contributes to the literatures on path dependence and path creation by elaborating these in the context of temporary inter-organizational projects and by integrating path research with stakeholder research.

The paper is organized as follows. A review of the literature on path dependence, path creation, and stakeholder dynamics during a project's early stage is followed by a description of the research method. The third section presents an empirical account of the Tapiola project's early stage, and the fourth section elaborates inductive reasoning on the Tapiola case, based on an interpretation of early project dynamics informed by research on path dependence and path creation. The final section discusses the implications of these findings for project management and path dependence and path creation research. In addition, managerial implications and multiple avenues for further research are suggested.

\section{THEORETICAL BACKGROUND}

\section{Path dependence and path creation in multi-stakeholder projects}

In the pioneering works of David (1985) and Arthur (1989), the idea of path dependence was introduced to explain the dominance and persistence of technologies that are not optimal in terms of technological or economic efficiency. The essence of path dependence is that our choices are conditioned by choices we have made in the past.

While now a well-established construct of modern organization theory, much confusion remains about the underlying logic of path dependence in organizations (Sydow et al., 2009). In particular, there has been criticism of the vague and metaphorical labeling of many processes in which "history matters" as path-dependent. This also applies in project contexts, as all human activity and decision-making is influenced in one way or another by history (Manning and 
Sydow, 2011). To address the shortcomings of this unduly broad and holistic approach to path dependence, Sydow et al. (2009) developed a dynamic framework, dividing the emergent process of path dependence into three distinct stages, commencing from (1) singular historical events, which may, under certain conditions, (2) become self-reinforcing dynamics that may lead to (3) organizational lock-in (Sydow et al., 2009). In particular, the notions of increasing returns and self-reinforcing mechanisms are at the heart of path dependence. Increasing returns refers to how the cost of switching from one option to another increases over time, leading ultimately to lock-in, where the path is irreversible - that is, flexibility is nonexistent, and the actions and decision logics of the actors follow a predominant mode (Pierson, 2000).

Levering et al. (2013) demonstrated how various self-reinforcing mechanisms explained lock-in in the context of an inter-organizational project in the shipbuilding industry. In such an organizational context, the various self-reinforcing mechanisms at play may include coordination effects, complementarity effects, learning effects, and adaptive expectation effects. Coordination effects are associated with the efficiency of human interactions or organizational operations, based for example on the assumption of efficiency in following shared rules during a project. Complementarity effects relate to the synergies within a bundle of resources, rules, and practices (Sydow et al., 2013) that make it more attractive to persevere with a chosen solution. For example, project-based firms offering complex products and systems tend to rely on the synergies of bundled resources and fixed practices that have been developed over the years with their systems suppliers. Learning effects refer to how capacity or skill in performing an operation or task improves through repeated performance; these effects are widely addressed in the project literature, as in Brady and Davies (2004) and Brady et al. (2005). Adaptive expectation effects relate to the interactive building of preferences among social actors, leading to the emergence of 
a dominant solution (Sydow et al., 2009). It follows that lock-ins may be both cognitive and normative, tied to the identities and interests of stakeholders (Lamberg et al., 2008).

The concept of path dependence itself has also been called into question. The key criticism is that path dependence does not allow for the possibility of active agency and fails to consider the strategic shaping activities of actors in deviating or intentionally breaking away from a certain path. To address these shortcomings, Garud and Karnoe (2001) and Garud et al. (2010) proposed the contrasting perspective of path creation. According to Garud and Karnoe, path creation suggests that "entrepreneurs may intentionally deviate from existing artifacts and relevance structures, fully aware they may create inefficiencies in the present, but also aware that such steps are required to create new futures" (2001, p. 6). Consequently, the ability to discover (Shane and Venkataraman, 2000) and to mindfully deviate from expected paths lies at the heart of path creation processes, along with the role of active agents (Garud et al., 2010).

Entrepreneurial action and path-breaking behavior during the early stages of a project have been identified as especially salient features, particularly in the case of innovative and vanguard projects (Davies and Brady, 2015; Frederiksen and Davies, 2008).

In their conceptualization of path creation processes, Garud and Karnoe (2001) identified a number of mechanisms that are of relevance for path creation: boundary spanning activities, generating momentum in new directions, translating ideas, breaking frames, mobilizing resources, and building powerful collectives. Boundary spanning activities refer to processes in which actors share their ideas persistently, making them meaningful for and through interaction with others. This type of transformation is necessary to overcome the resistance and indifference of other stakeholders. Generating momentum is also seen as an important path creation process in a project's early stage in shaping the preferences of stakeholders. According to Garud and 
Karnoe (2001), the ability to mobilize a coalition of actors is especially relevant when path creation efforts encounter resistance and inertia. Project managers typically face strong resistance to their path creation efforts and resort to a range of strategies (Artto et al., 2008) to counter such forces. Path creation processes have been shown to play a central role in the diffusion of innovations, as for instance in the construction sector (Boland et al., 2007) and in the emergence and development of project-based industries (Hellström et al., 2013).

There is growing interest in the integration of the concepts of path dependence and path creation, which were commonly treated separately. While Sydow et al. (2009) emphasized the need for detailed examination of how actors can break away from paths, Garud and Karnoe (2010) have argued the need to consider both the intentional action of agents and the hidden dynamics of selfreinforcing processes for a more balanced view of path dependence and path creation.

\section{Management of the early stage of multi-stakeholder projects}

The question of when a project actually starts is a fundamental one. Over the years, there has been increasing emphasis in project research on the management of the early development work, project front-end, initiation and pre-project phases (Lundin and Söderholm, 1995; Miller and Lessard, 2000; Cova et al., 2002, Matinheikki et al., 2016). More recently, project management scholars have also begun to address the fundamental role of project's early stages in actual outcomes, effectiveness, and long-term value creation in multi-actor projects (Artto et al., 2016; Matinheikki et al., 2016; Merrow, 2011; Morris, 2013, Samset and Volden, 2015). In general, the early stage of a project is characterized by a high level of uncertainty and ambiguity and by dynamic stakeholder interactions (Morris and Hough, 1987; Hellgren and Stjernberg, 1995; Floricel and Miller, 2001; Kolltveit and Grønhaug, 2004). It is during this period that the overall 
task and the project's common goals, objectives, concept, design options, scope, and direction are shaped through the interactions of an evolving network of multiple organizations.

Research on networked projects includes contradictory views of their early stage. While some scholars maintain that any uncertainties and ambiguities must be addressed through highly formal and linear planning processes and management tools (e.g., Morris and Hough, 1987; Kolltveit and Grønhaug, 2004), others argue that, because of the complexity and fuzziness of the early phase, formal project planning tools and a rational, opportunistic mindset are unlikely to produce the best possible outcome (e.g., Hellgren and Stjernberg, 1995; Lundin and Söderholm, 1995; Floricel and Miller, 2001). Specifically, according to the latter perspective, the early stage of a project should be seen as an iterative and drifting process of organizing, influenced by unexpected stakeholder influences and shaping events. During this early stage, individual stakeholders seek to stabilize their position in the project network (DeFilippi and Sydow, 2016; Hellgren and Stjernberg, 1995), and to maximize value creation in terms of how their own objectives relate to shifting project-level objectives. Despite a few valuable contributions concerning the role and behavior of central actors such as clients (Samset and Volden, 2015), institutions (Miller and Lessard, 2000), and stakeholders (Aaltonen et al., 2015), empirical knowledge and theoretical understanding of the phenomena that may unfold during the early stage of a project remain limited, decontextualized, static, and focused on the role of single organizations. In particular, the role of project stakeholders and their influencing behavior is considered crucial in understanding early stage dynamics and goal formulation in a network of multiple organizations.

\section{RESEARCH METHOD}

\section{Research strategy}


We chose to apply a process approach (Bizzi and Langley, 2012) in studying the early stage (2000-2012) of the Tapiola project. In adopting this approach, we were particularly interested in analyzing the formation of the path among the networked stakeholders in terms of how and why events, choices, decision-making, and stakeholders' roles evolved over time in the network of the case project (Langley, 1999).

A case study approach is appropriate in this context, as it focuses on the dynamics within the given setting (Eisenhardt, 1989). The long and dynamic early stage of the Tapiola project featured a complex stakeholder setting that was suitable for investigation of the dynamics of the project's goals, design and scope. Our theoretical reasoning here is primarily inductive; based on the case analysis and interpretation, we build on the existing constructs of path dependence, path creation, and stakeholder research to develop new knowledge of the dynamics of a project's early stage.

According to Yin (2009), single cases are commonly selected as unusually revelatory or extreme exemplars, or because they afford unusual research access. For a number of reasons, the early stage of the Tapiola project provides an excellent single case study setting in which to study processes of path dependence and path creation. First, as Tapiola—one of the major urban districts in the Helsinki capital area-is known globally for its architecture, cultural heritage, and planning principles, the historical forces and inertia associated with the area's architectural uniqueness had clear impacts on the direction of the renewal project. Second, the Tapiola project is an evolving multi-stakeholder constellation, and a number of stakeholder activities, choices, and decisions that shaped thesign and scope of the project can be identified in the early stage. Third, the project's early stage witnessed a radical change in the goals and scope of the project. This combination of history-related inertia, radical changes in direction, and the stakeholder 
network provided an opportunity for a deeper exploration of path dependence and path creation and the role of multiple stakeholders in these processes.

\section{Empirical context: Tapiola as an urban renewal project in a historically valued area}

The present study focuses on the urban renewal project of the commercial center of Tapiola, which was built largely during the 1980s and is the main trading and service area. However, the history of the Tapiola heritage district (designated in the 1950s) has implications for what if any changes are likely to be accepted by those claiming an interest in conserving Tapiola's heritage. Figure 1 illustrates the district's historical context as a chronology from the 1940s to the 1990s.

In late 1990s and early 2000s, Tapiola lost some of its commercial attractiveness, and there were clear signs of a need for renewal. In particular, the degeneration and decay of buildings, walking routes, and public areas in the commercial district were seen to be slowly eroding Tapiola's attractiveness. In 2000, as a response to this decline, the City of Espoo produced a development plan for Tapiola's commercial center area. This signaled the starting point for renewal of the district, involving a number of stakeholders who supported the renewal of the Tapiola district through a joint effort based on the initial development plan. Those stakeholders included the City of Espoo and various property owners, principal among which was LocalTapiola Real Estate Asset Management Ltd. (TRE) (See Appendix 1 for a detailed key stakeholder list).

The renewal project's early stage, which we analyzed as three distinct phases, lasted from 2000 to 2012. Construction work commenced in 2013, and completion of the renewal of the whole center area is scheduled for 2020. As is typical of large urban development projects, the early stage of the Tapiola project consisted of a multi-organizational constellation of private and public organizations that evolved continuously. Figure 2 presents a timeline of key events in the Tapiola project's early stage. 
Romanticism and heimat thinking

- The time after the 2nd World War: material shortages and new housing designs Von Hertzen's book Home or Barracks for Our Children describing the ideals underlying the new designs of Tapiola
Naturalism, low architectural

density, family

- The Housing Foundation established for planning and building a Garden City

- An open competition for Finnish architects to plan the Tapiola Center won by Aarne Ervi (1953)

- Tapiola chosen as the name of the garden city through a public competition (1953)

- The first residential areas of Tapiola (1954)
Compact yet still garden-like grid planning

- Tapiola gains international recognition

- The Tapiola center developed strongly, Aarne Ervi as the main architect

- The Central Tower (1962) and Tapiontori shopping center (1968)

- The expanding plan of the central area (1967)
Functional city center planning Stabilization, shift of

- The Tapiola center focus to the development

expansion plan of other urban areas

released and - Decreased construction

executed by

- Decreased construction
intensity, focus of

development

Tapiola Garden hotel (1974) to other areas in Espoo

- Sokos shopping center (1979) • Stockmann shopping

Waterfallhouse (1985)
Era of decaying

- Urban planning problems: concerns about suitability of

additional

buildings

- Decaying of buildings

\begin{tabular}{|c|c|c|c|c|c|}
\hline 1940 & 1950 & 1960 & 1970 & 1980 & 1990 \\
\hline
\end{tabular}

Figure 1. Tapiola district's history from the 1940s to 1990s

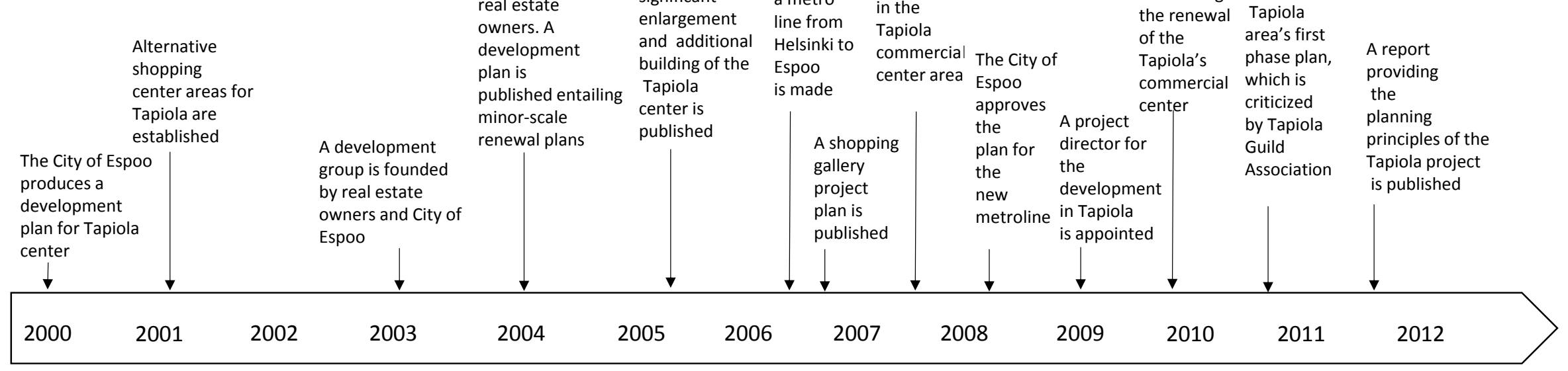

Figure 2. A timeline of key events of the Tapiola project's earl 


\section{Data collection}

The evidence from the case study is primarily qualitative in nature and combines different data sources that facilitated the triangulation of information. Data from sixteen semi-structured interviews were complemented by the initial collection of archival material related to the Tapiola district, covering its whole history, its stakeholders, and the ongoing renewal project. This documentary material included newspaper clips, memos, press releases, and media reports on Tapiola and the urban area development project, as well as books about the ideals of Tapiola, publicly available documentation on the city planning council's preparatory documents, and other city planning documents. These documentary sources enabled us to construct an understanding of the Tapiola district's context and the early stage of the Tapiola project, its stakeholders and stakeholder network, and the interests and goals of stakeholders, as well as changes in the project's goals, design plans and overall scope.

This understanding was then deepened through interviews with individuals representing the project's active stakeholders. In addition, we interviewed the project's key architect and another experienced architect with a long history of underground construction projects in the Helsinki metropolitan area. In total, sixteen interviews were conducted during November 2011 and December 2014 by a team of four researchers. The interviews lasted between 61 and 133 minutes and were tape-recorded and transcribed. They were semi-structured, in the sense that the research team had already identified key themes to be discussed with informants. These related to important project events and stakeholders and the dynamics of their interaction, as well as to the goals and objectives of stakeholders. Questions were tailored to fit the profile of each interviewee. The idea was to gain a detailed understanding of what was done, when, by whom, and why - that is, an account of events, activities, and choices, ordered over time. From the 
perspectives of path creation and path dependence, the sequence of events related to these

processes was also considered important. Finally, two results workshops to discuss our findings with the interviewees were organized in January 2012 and December 2014. Table 1 summarizes the interview details and the documentary data used to support our analysis.

\section{Table 1. Data sources}

\begin{tabular}{ll}
\hline INTERVIEW DATA & \\
\hline Interviewee title & Interviewee organization \\
\hline Project Manager & City of Espoo \\
Architect & Pensioner \\
Real Estate Manager & Tapiola Real Estate \\
Fund Manager & Tapiola Real Estate \\
$\begin{array}{l}\text { Head Manager of Real } \\
\text { Estate Investment }\end{array}$ & Tapiola Real Estate \\
Property Manager & City of Espoo \\
$\begin{array}{l}\text { Leader of Urban Planning } \\
\text { Unit }\end{array}$ & City of Espoo \\
$\begin{array}{l}\text { Correspondent of } \\
\text { Livelihood }\end{array}$ & City of Espoo \\
Headquarters Manager & City of Espoo \\
$\begin{array}{l}\text { Manager of Real Estate } \\
\text { Developing }\end{array}$ & Tapiola Real Estate \\
CEO & \\
Chairman and Member & Residents' Association Tapiola Guild \\
Architect & SARC, Architect company \\
Department Manager and & National Board of Antiquities \\
\hline
\end{tabular}




\begin{tabular}{ll} 
ARCHIVAL DATA AND DOCUMENTS & \\
\hline Public data source type & $\begin{array}{l}\text { Quantity } \\
(\mathrm{N}=215)\end{array}$ \\
\hline Helsingin Sanomat (leading Finnish newspaper) & 64 \\
Länsiväylä (large newspaper in capital region) & 55 \\
Tekniikka \& Talous (largest Finnish magazine focusing on technological and economic & 6 \\
innovations) & 2 \\
Talouselämä (largest Finnish financial weekly and most respected economic journal) & 13 \\
Other newspapers & 16 \\
Development reports & 11 \\
Plans / illustrations describing the project & 17 \\
Documents / records & 9 \\
Press releases & 3 \\
Presentations / brochures & 16 \\
Written public statements & 3 \\
Records / legislations & \\
\hline
\end{tabular}

\section{Data analysis}

We commenced the analysis of data by constructing a description of the Tapiola project's early stage (2000 to early 2012). The purpose of this account was to describe the entire process in chronological order by building a database from our sources. This process revealed clear changes in the goals, design solutions and scope of the Tapiola project. During the earliest phase, the plans were modest and strongly associated with the rich history of the area; subsequently, more radical ideas and plans emerged among the stakeholders. This early observation prompted us to search for explanations from existing theories; of these, path dependence and creation seemed the most promising. 
Following construction of the case description, the process of empirical interpretation and theorization commenced. Our inductive analysis focused on understanding how path dependence and path creation processes were manifested during the Tapiola project's early stage and in the formation and development of the project's goals and direction. The data were content analyzed and coded by one of the authors. During the first coding round, we looked for descriptions and evidence concerning the project concept, goals, scope, design plans and their changes. We then proceeded to search for textual data related to events, decision-making, or plans as indicators of path dependence and creation. For example, interviewees' references to expectations concerning low-rise buildings because of the historical relevance of this planning principle were coded as one such indicator. During this process, we included the timing of any such indicator and any explicit mention of their connection to the project's plans, design and their changes or to particular stakeholders. We then categorized these observed indicators of path dependence and path creation in terms of the literature's key theoretical constructs, such as initial conditions and the self-reinforcing mechanisms of coordination effects, complementary effects, learning effects, and adaptive expectations (Sydow et al., 2009), as well as the path creation activities of boundary spanning, generating momentum, translating ideas, breaking frames, mobilizing resources, and building powerful collectives (Garud and Karnoe, 2010). Next, we looked for changes in stakeholder positions during the project's early stage in data referring to the role of stakeholders, their relationships, or changes in these. Finally, we sought to combine and ground theoretical interpretation in emergent findings, insights, and empirical observations.

\section{Reliability and validity}

We were particularly concerned to ensure the high validity and reliability of our findings (e.g., Yin, 2009), and the methods of achieving this are summarized in Table 2. 
Table 2. Means used to ensure validity and reliability

\begin{tabular}{|c|c|}
\hline Validity type / reliability & Means used in the study \\
\hline Objectivity & $\begin{array}{l}\text { Transparent and explicit data collection including } \\
\text { documentary and interview data, and an analysis by } \\
\text { developing and following a clear research design } \\
\text { Organizing two research workshops (January 2012, } \\
\text { December, 2014) to discuss the findings with the key } \\
\text { interviewees }\end{array}$ \\
\hline Reliability & $\begin{array}{l}\text { - Data were collected from a broad set of sources and of } \\
\text { carefully selected informants, which represented the different } \\
\text { key stakeholders of the Tapiola project } \\
\text { - All interviews and results workshops were conducted by } \\
\text { several researchers; one led the interview and the other } \\
\text { members complemented the interviews and took notes } \\
\text { - Emergent findings and key insights from the interviews were } \\
\text { discussed among researchers after the interviews Recording } \\
\text { and transcribing all sixteen interviews } \\
\text { - Development of a database } \\
\text { - Cross-checking and discussing the analysis to ensure } \\
\text { consistency and agreement among researchers }\end{array}$ \\
\hline Construct validity & $\begin{array}{l}\text { Use of theoretical frameworks and the indicators of path } \\
\text { dependence, path creation and stakeholder management as } \\
\text { guidelines in the data analysis and empirical study } \\
\text { - Interview data was analyzed and presented to a focused } \\
\text { group of interviewees twice for cross-checking and ensuring } \\
\text { validity of the findings } \\
\text { - The results of the analysis were sent for review for the } \\
\text { interviewees }\end{array}$ \\
\hline Internal validity & $\begin{array}{l}\text { Data collection of the actual and ongoing project to reduce } \\
\text { recall bias and enhance data accuracy } \\
\text { - Interviews were complemented with documentary data to } \\
\text { enable triangulation and to eliminate recall bias } \\
\text { - Interviewees were offered anonymity to encourage open } \\
\text { discussion and improve data accuracy }\end{array}$ \\
\hline External validity & $\begin{array}{l}\text { - Clear, rich and detailed description of the research context } \\
\text { and of the Tapiola project's progression and events over time } \\
\text { - Interview data was analyzed and presented to a focused } \\
\text { group of interviewees for cross-checking and ensuring } \\
\text { validity of the findings } \\
\text { - Establishing the boundaries for analytical generalizations and } \\
\text { for the transferability of the theoretical ideas }\end{array}$ \\
\hline
\end{tabular}

\section{Limitations}

While a qualitative approach is appropriate for identifying and describing processes of path dependence and path creation in the present context, we recognize that the approach has also some key limitations. First, Tapiola is an exceptional city district, with a global architectural 
reputation and history, making it particularly fruitful for the study of path dependence processes. Second, as the observed phenomena involve multiple stakeholders and interrelated processes, it is challenging to draw causal inferences of any kind. Third, the fact that the studied project network was undergoing a major transition may have had implications on our findings, when compared to more stable project network set-ups during the project's early stage. Finally, while our informants included representatives of the key stakeholders of the project network we were not able to access all the stakeholders related to the project. This would have ensured an even more holistic and multi-dimensional perspective to the early stage of the Tapiola project.

\section{EMPIRICAL ACCOUNT OF THE TAPIOLA PROJECT'S EARLY STAGE}

Our empirical analysis revealed three distinct sequential phases in the early stage of the Tapiola project. Phase I (2000-2006) was an initial period of slow progress and reliance on the past; Phase II (2006-2010) was characterized by dynamic changes in the stakeholder network and the emergence of a completely novel path for the direction and scope of the project; and Phase III (2010-2012) was a period of enlargement and institutionalization of the new path.

\section{Phase I (2000-2006): Reliance on history}

At the turn of the millennium, officials of the City of Espoo and other stakeholders began to notice signs of Tapiola's decreasing attractiveness. Residents contacted city officials and complained about the "unkempt appearance" of the district, and commercial tenants worried about a drastic decline in sales. While other attractive commercial and shopping centers were being built close to Tapiola, the area itself was on the road to "slow and painful death," as one interviewee put it. Once famous for its active cultural life and garden city brand, Tapiola was losing its competitive advantage and its attractiveness as a commercial district. 
To counter this trend, the Tapiola project was initiated, and in 2000, the City's planning unit produced a development plan for Tapiola's commercial center. The plan listed some modest proposals for the area's enhancement; the general thrust of the scheme was to increase Tapiola's attractiveness through such measures as renovation of tiling and lighting, renewal of parking arrangements, and construction of glass canopies between buildings. The direction and scope of the project at that time were described by interviewed property owners who participated in the project's managerial meetings as "remarkably modest" and "small-scale," and the project was characterized as "tinkering," "a facelift," and "keeping busy." The project's perceived lack of ambition was encapsulated in the comment of one interviewee (from TRE) directing the project coordination group: "At that time, in 2002, everyone was remarkably careful about any development of the city center-small suggestions only."

To facilitate the renewal project, a co-ordination body called Tapiola Area Development Ltd. was founded in 2004 by Tapiola's real estate owners. One of this organization's goals was to establish a working and legitimized interface between property owners and the City of Espoo in order to progress the renewal project. The City of Espoo was not itself a major property or land owner in the area, posing additional challenges for the project. A project report was published in that same year; like the 2002 report, this document again listed key future activities and subprojects to rejuvenate Tapiola. These were similar in ambition to the previous report and included proposals such as a heating system under the marketplace area and a gallery hall.

However, these early development plans of the project faced a number of challenges. First, some stakeholders were of the opinion that, as one interviewee put it, "We should let Tapiola stay as it is, and the scenery should be untouchable." Among those stakeholders who clearly objected to at least some elements of the plans were the Guild of Tapiola and the National Board of 
Antiquities. Tapiola and its history clearly stirred the emotions of some stakeholders, not least in relation to the district's garden city image and its status as a cultural heritage site. Specifically, the characteristic spacious, low-rise building style was an element that many wished to protect; indeed, at that time, all stakeholders shared the cognitive frame that building upwards was not an option because of Tapiola's protected skyline - most notably, the Central Tower. Built in 1967, this celebrated tower was not located in the commercial center but adjacent to it in the architectural heritage area of the historic garden city. The Tower was seen to define an incontestable building height limit; as one representative of the City of Espoo humorously described it, "Central Tower is your God, you shall have no other gods that would rise higher." As this dominant mindset guided the logic of all stakeholders, the Tower effectively defined boundaries for the planning of the Tapiola project during those early stages.

In addition to the restricted mindset of stakeholders, the fragmented property ownership structure - that is, the stakeholder network—also proved challenging for the proposed renewal. For historic reasons, real estate ownership within Tapiola's commercial center was distributed among a heterogeneous group of stakeholders, ranging from shoe sellers to institutional investors; as a consequence, there was no single powerful stakeholder who could drive the project forward. In addition, the players seemed content with how the work of developing the area was shared and how different businesses complemented each other. Despite attempts at coordination, the conflicting interests and business objectives of this fragmented set of stakeholders proved difficult to align. In these circumstances, decision-making proved challenging, and the planning process was dominated by compromise.

\section{Phase II (2006-2010): Emergent path creation processes}


The period 2006-2010 saw some very significant changes in the scope of the Tapiola project. First, in 2006, the decision was made to build a metro line from Helsinki to Espoo. In 2008, Espoo City Council decided that Tapiola would be on the metro route, marking a new era for the Tapiola project. Interviewees maintained that it was the metro decision that set real processes of change in motion, although these proceeded slowly: "It must have been the decision that the metro is coming that molded the mindsets of the stakeholders; all of those who had been involved understood that they need to do something significantly more and new, and in a completely different way."

Following the initial metro decision in 2006, plans developed rapidly, and new visions emerged. These included a plan for a shopping gallery attached to the future metro station and a service tunnel under the commercial center. Other new plans included parking facilities to be dug out of the base rock, providing 3,000 new parking spaces. Although many issues remained unresolved, stakeholders seemed overtaken by a fresh spirit of hope. As one TRE interviewee described the process, "It was during that time ... our vision for the development of the Tapiola Commercial Center gradually developed."

TRE's emerging strategy was to safeguard and increase its ownership within the Tapiola commercial center area. This would also strengthen TRE's position within the scheme, and its more prominent role facilitated a smoother period of development for the project. This development path also aligned with the interests of the City of Espoo, which had been looking for a solution to the issue of fragmented ownership. As one representative of the city put it, "TRE was almost like a savior. They could promote the project, and they had a big enough financial interest to reduce ownership fragmentation. They assumed the role of a leader." 
As TRE increased its ownership in the center, planning cooperation strengthened between TRE and the City of Espoo. These interactions became daily and embedded, particularly between the zoning department and TRE's architects, and a range of coordinating committees were also established. Under these changed conditions, new plans and scope for the project began to take shape. TRE's original approach was based on the existing buildings and additional building rights, but massive rebuilding was not part of their plans. Interviewees from TRE intimated that the plans, designs and ideas at that time remained small-scale, dominated and bounded by the unique history of Tapiola: "At that time in 2008, our ideas about the center...really...minimal. Our assumption was that we could not tamper with the city center anyhow. We thought that the only way to extend our ownership was to go below ground level. And that the facades were protected and that regulated spirit-that we thought was tacitly expected. Where did we really get these ideas, that we can just do something small-scale... that we could not do something extraordinary. It was as if someone was holding down the kettle lid." This "kettle lid" was the stakeholders' shared assumption that the heritage of old Tapiola was untouchable, and that the Central Tower acted as a symbol for the entire region. Everything else (i.e., new high-rise buildings) was kept under this lid, preventing anything from "growing" upwards above that height.

In 2009, the City of Espoo made the decision to invest heavily in the development of Tapiola. A balance unit was established to ensure direct allocation of development money for the project, and a project director — noted for his ability to lead challenging and complex projects—was hired. As his first task, the project director began to promote the Tapiola project by building embedded relationships with the various stakeholders, communicating and engaging in multiple dialogues. His commitment and energy, as well as his ability to see the project as a whole, was 
mentioned frequently by our interviewees. The project director had also internalized the contextualized historical burden of the project and its effects on the project:

"The center of Tapiola has a strange history in the Finnish context. This is not just about 'this looks like this and is built like this' but also when this was built, by whom, through what process-it all plays a central role in this project."

The project director understood that something "more dramatic and courageous" was needed. During this period, major changes in the overall scheme of the renewal project began to emerge as the stakeholders struggled to find a commercially and financially sustainable concept and overall scheme. The project's viability depended on increasing the number of residential units. To cover the costs of the metro infrastructure investment, the only financially realistic plan was to build higher buildings, with apartments above the business premises. According to the interviews, it seems that the project director of the City of Espoo, along with certain planning architects, was among those who questioned the project's planning principles, which had for so long restricted the thinking of stakeholders.

Through a period of intense interactions between the project director, relevant senior managers at TRE, architects, planning architects, and members of the City Planning Committee, the mindset gradually began to change, and a new vision and direction emerged. This included, for example, eight-storey buildings, the demolition of old buildings, and a complete new build for much of the center. The processes informing these changes were fuzzy and hard to grasp, even for the stakeholders themselves, and our interviewees struggled to make sense of how changes actually emerged in the initially highly restricted overall project plan, and how the unquestioned primacy of the Central Tower was overturned. Most of the interviewees indicated that the project director 
played a crucial role; as one recalled, "I first heard about the new ideas from the project director of City of Espoo himself, when he said that we need to do something big."

However, despite these changes, TRE representatives remained restricted in their thinking and struggled with the role of history in Tapiola's future path: "I do not know whose ... 'kettle lid' it was that set the maximum height, but we still thought that the buildings could not be that tall—at maximum, eight-storey buildings." During 2009 and 2010, TRE seemed to have an idea that something big was changing: "It was during early 2009 that the first ideas emerged-what if we could get something, just little bit more, above the business premises? Then we thought 'OK, a little bit more height,' and when the city said OK, we started thinking 'OK, a little bit more still.' And then we started thinking 'Why are we honestly thinking in this way-renovating? Why don't we just dig it away and build more?' This plan started to feel a little better in 2010. And then we started to think 'maybe still more,' and these plans were made public, and the neighbors were also getting their buildings up. It felt as if someone was removing the kettle lid."

As described, the process of "removing the kettle lid," by raising the maximum height of buildings from eight storeys to eighteen, unfolded during 2010 and early 2011. In 2011, 18storey buildings were already planned. This plan was also approved by the City Planning Committee, but why and how the process actually took this course remained a mystery to most of the stakeholders.

\section{Phase III (2010-2012): Institutionalization of the new path}

Dramatic changes in the project's plans and scope emerged during 2010-2011, and suddenly, the plans started to look totally different. According to one TRE interviewee, "The story, based on our initial plans, was totally different from what we have today. These pictures, how they look 
today, and all those ideas behind them — they were totally different before. Now, we are building high-rise buildings and tearing down and rebuilding much of the central area."

After these drastic changes and the project's redirection, the stakeholders searched continuously for new value-adding elements and businesses. Ideas were advanced about green roofs and sustainable buildings, including a proposal to cover one of the main roads with a green roof. The project director continued to look for elements to increase the project's value and legitimacy. During this period, emphasis was also placed on the continuous incorporation of new ideas, and the stakeholders began to see change as a natural and expected phenomenon.

A report prepared by the project director, formalizing the development principles that would guide planning and design, was published in November 2011. Throughout the fall of 2011, public hearings were arranged and press releases were published. TRE continued to further strengthen its position in the area by acquiring central properties. The most significant of these transactions was the acquisition of property utilized by Stockmann's high-end department store from Wereldhave Ltd. Despite resistance to the high-rise building style from the Tapiola Guild Association and the National Board of Antiquities, plans moved forward. In September 2011, the City Planning Committee officially accepted the proposed plans.

During 2011, the project also gradually achieved acceptance among some of those who had originally adopted a critical stance. In effect, the project's changes of goals and direction came to represent courage, as illustrated in the following quote from a member of the City Planning Committee: "The Tapiola case can act as an example for other urban renewal projects because of its attitude to change and its courageous approach to planning." 


\section{THEORETICAL INTERPRETATION}

In explaining how the project's path and inherent direction unfolded, our analysis revealed processes of path dependence and path creation in three distinct phases of the early stage: I) reliance on history; II) emergent path creation processes; and III) institutionalization of the new path. Building on this empirical account of the early stage of the Tapiola project, the theoretical notions of path dependence and path creation were used to analyze and interpret development processes and the causes of change. Table 3 summarizes the empirical findings.

The findings reveal that while path dependence processes predominated during the "reliance on history" phase, there was a short transitional period at the start of Phase II ("emergent path creation processes") when there were visible indicators of both path dependence processes and path creation processes. Subsequently, path creation processes began to predominate.

Figure 3 integrates our observations as a process model, outlining the path of the project in its early stage and identifying the three distinct phases. This visualization builds on Sydow et al. (2009); stars represent the range of feasible design options and potential directions for the project; the shaded area represents the range of available design options; the unbroken line represents the path of the project, and the dotted line indicates the emergent novel direction. Each phase is characterized by aggregate path dependence (PD) and path creation (PC) processes. 
Table 3. Evidence of path dependence and path creation processes in the three phases during the early stage of the Tapiola project

\begin{tabular}{|c|c|c|c|}
\hline Phase & Project direction & Stakeholder network & $\begin{array}{l}\text { Empirical evidence of path dependence (PD) and path } \\
\text { creation (PC) processes }\end{array}$ \\
\hline $\begin{array}{l}\text { Phase I (2000- } \\
\text { 2006): } \\
\text { Reliance on } \\
\text { history }\end{array}$ & $\begin{array}{l}\text { Modest and small-scale design and renovation } \\
\text { plans: e.g., renewal of tilings } \\
\text { Project's designs and scope's strong reliance on } \\
\text { the history and design rules of historical Tapiola } \\
\text { - Challenges in agreeing on the project's overall } \\
\text { purpose, goals, and scope } \\
\text { Planning principle: center to remain untouchable, } \\
\text { Central Tower height dominates, Tapiola's old } \\
\text { design rules }\end{array}$ & $\begin{array}{ll}\text { - } & \text { Large number of heterogeneous stakeholders } \\
\text { - } & \text { No one clear leader of the stakeholder network } \\
\text { - } & \text { Non-alignment of goals and } \\
\text { business interests of stakeholders } \\
\text { - } & \text { Fixed stakeholder positions } \\
\text { - } & \text { Coordination body's decision making } \\
\text { restricted by stakeholders' fragmentation } \\
\text { - } \\
\text { Identity-based interests of stakeholders } \\
\text { predominant } \\
\text { City of Espoo as the hub of the stakeholder } \\
\text { network }\end{array}$ & $\begin{array}{l}\text { - } \quad \text { Structural lock-in, with fragmented, heterogeneous stakeholder } \\
\text { network structure and fixed stakeholder positions (PD) } \\
\text { - } \quad \text { Inability of stakeholders to carry out significant improvement } \\
\text { projects( PD) } \\
\text { - } \quad \text { Experience of increasing returns on Tapiola's brand value (PD) } \\
\text { - } \text { pomplementary effects: stakeholders' complementary roles in the } \\
\text { project (PD) } \\
\text { Coordination effects: stakeholders' joint routines and practices of } \\
\text { acting together and scoping the project (PD) } \\
\text { Learning effects: stakeholders' own capabilities and skills on how to } \\
\text { work in such projects (PD) } \\
\text { Adaptive expectations among stakeholders: reliance on Tapiola's } \\
\text { history (PD) and expectations about maximum building height and } \\
\text { untouchability of the center (PD) }\end{array}$ \\
\hline $\begin{array}{l}\text { Phase II (2006- } \\
\text { 2010): } \\
\text { Emergent path } \\
\text { creation } \\
\text { processes }\end{array}$ & $\begin{array}{l}\text { - } \quad \text { Glass gallery plans } \\
\text { - } \quad \text { Building "down": underground parking hall plan } \\
\text { - } \quad \text { Renovation of old buildings and their facades } \\
\text { - } \quad \text { Center to be left almost untouched } \\
\text { - } \quad \text { Plans to make the center more viable through } \\
\text { new buildings and renovation } \\
\text { - } \\
\text { Emergence of the potential for something more } \\
\text { radical ("what if" thinking) }\end{array}$ & $\begin{array}{l}\text { - TRE's increased salience through property } \\
\text { acquisitions and established relationships to } \\
\text { other stakeholders } \\
\text { - TRE's legitimate role as project leader } \\
\text { - } \quad \text { Reduced fragmentation of stakeholder network } \\
\text { in terms of the ownership } \\
\text { - Deepening of relationships between TRE, the } \\
\text { City of Espoo and the architects } \\
\text { TRE's identity change into a real developer } \\
\text { and increased financial interest } \\
\text { A new key stakeholder: project director of the } \\
\text { City of Espoo appointed }\end{array}$ & 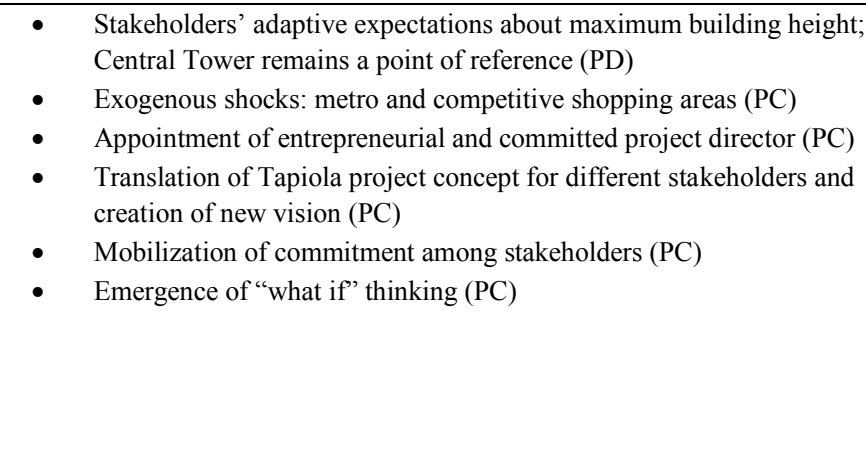 \\
\hline $\begin{array}{l}\text { Phase III (2010- } \\
\text { 2012): } \\
\text { Institutionalizat } \\
\text { ion of the new } \\
\text { path }\end{array}$ & 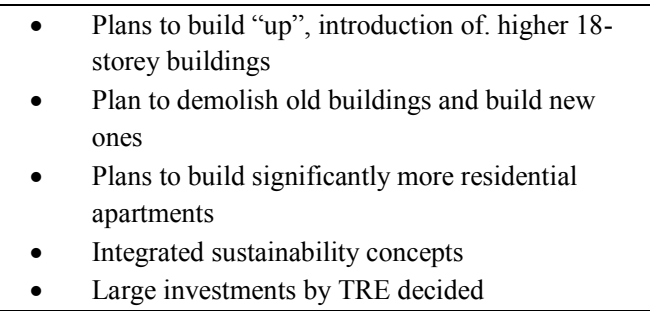 & $\begin{array}{l}\text { Two key players with aligned interests: TRE } \\
\text { and City of Espoo } \\
\text { - New stakeholders with value-adding elements } \\
\text { linked to the network } \\
\text { Increased acceptance for plans among external } \\
\text { stakeholders }\end{array}$ & $\begin{array}{l}\text { - Written theses, design rules and axioms for the planning project (PC) } \\
\text { - } \\
\text { Tew value-adding elements continuously pursued and linked to the } \\
\text { - Identity of the Tapiola project used as an exemplar of courage for other } \\
\text { renewal projects (PC) }\end{array}$ \\
\hline
\end{tabular}




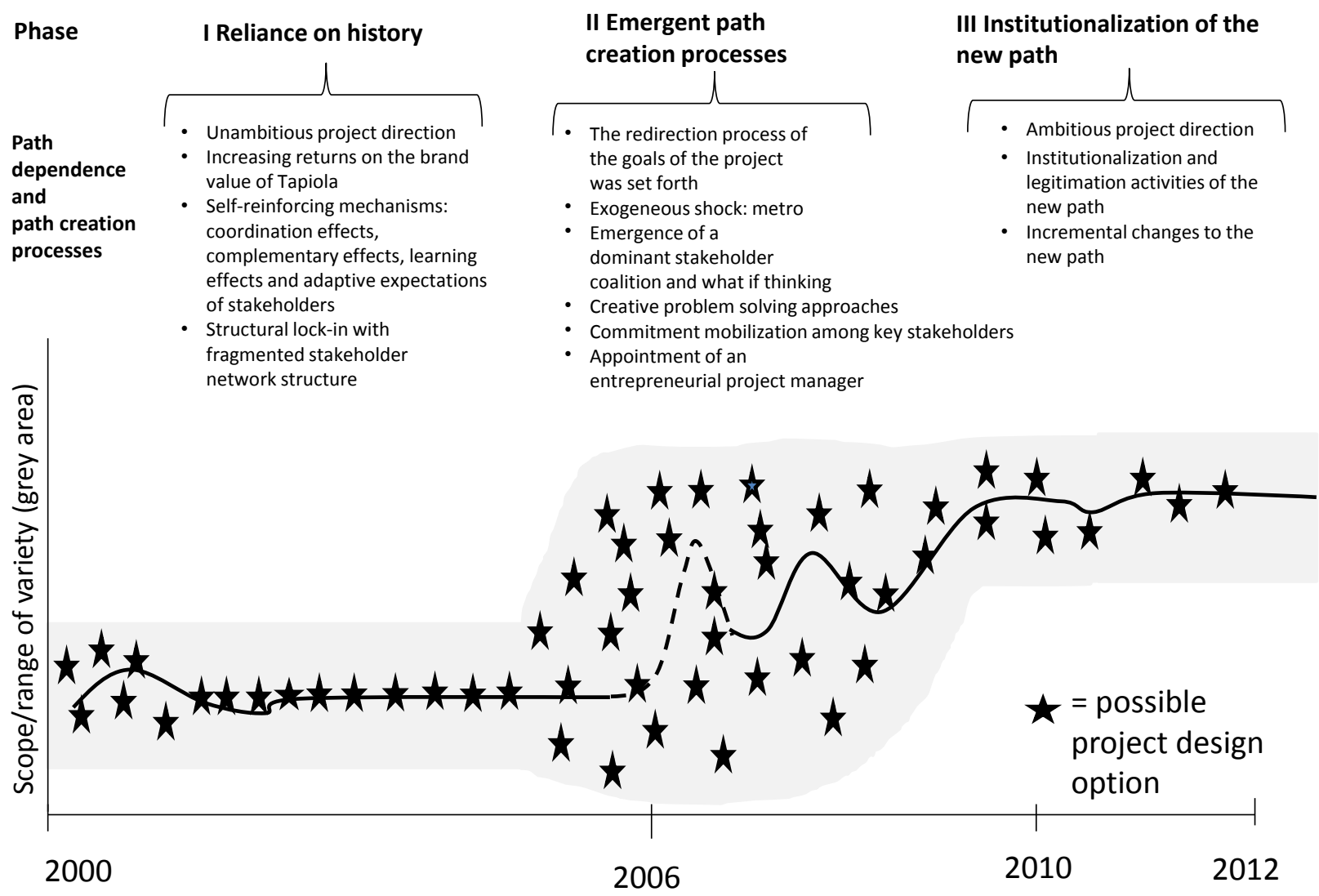

Figure 3. Path dependence and path creation processes in the early stage of the Tapiola project

\section{Path dependence processes during the early stage of a multi-stakeholder project}

The historical events that made Tapiola world famous long before the initiation of this project also restricted the project actors' approach to planning the development of Tapiola and so affected their choices and decision making in multiple ways at the outset. Increasing returns (David, 1985) such as the positive feedback effects of Tapiola's unique brand value meant that the district relied for too long on its traditional attractiveness. According to our findings, this 
reliance on historical resources created inertia and rigidity at the start of the project that proved challenging for the actors to escape. Our evidence indicates that the four self-reinforcing mechanisms of path dependence (Sydow et al, 2009) exerted a powerful influence on the Tapiola project's direction, particularly in the first "reliance on history" phase, leading ultimately to a state of lock-in. In this respect, our findings provide new knowledge of how coordination effects, complementary effects, learning effects, and adaptive expectation effects are manifested in the early stage of networked projects.

Coordination effects in the early stage of the Tapiola project built on benefits accrued through the rule-guided behavior of stakeholders (Lamberg et al., 1998). Our observations indicate that the interaction among project stakeholders was rendered more efficient by following the institutionalized rules (“Tapiola's planning principles"), with a consequent decrease in coordination costs, as stakeholders' behavior in relation to the renewal and its planning could then be anticipated. Therefore, it was highly tempting to adopt the internalized planning rules of historical Tapiola as a starting point for the project design.

Complementary effects included the tendency among key project stakeholders to support modest and small-scale project designs because these were considered to ensure the continuity and stability of their business positions in the network. Complementary effects were observed in the synergies that stakeholders expected from the interaction of their separate but interrelated resources and their habitual procedures, practices, roles, and routines (Pierson, 2000). For example, it was taken for granted that the role of the City of Espoo was to guide any major development projects in the district. This clearly saved on the mismatch costs of project design solutions that deviate from established practices. 
Learning effects were observed in the tendency among Tapiola project stakeholders to rely on their established skills and capabilities, making it less attractive for them to explore new or radical design options. In their efforts to renew and create, the stakeholders were for the most part mobilizing the past, still concerned to protect the garden city image. Faith in the positive effects of small scale renovations was driven by the reliance on Tapiola's spirit and attractiveness, encouraging the replication of old practices and exploitative learning (March, 1991). The inclusion of small-scale developments in the project plans also gained legitimacy and acceptance among stakeholders more easily than novel alternatives or critical evaluation of established structures and designs.

In addition, we found evidence of cognitive path dependence processes in the self-reinforcing mechanisms of adaptive expectation effects. It appears that the cognitions, mindset, and ambitions of stakeholders were restricted by the historical context of Tapiola in ways that the stakeholders themselves could not explain or make sense of. For example, according to our data, the dominant role of the Central Tower and the protection of the city center were institutionalized as shared and legitimate assumptions by a majority of stakeholders. These unquestioned underlying principles served as a starting point for the project's goals and design, confirming the self-reinforcing effects of adaptive expectations. In the uncertainty that is typical of a project's early stage, it is more tempting and rewarding for stakeholders to rely on design solutions that are also seen to be preferred by others (Sydow et al., 2009).

In addition to these new insights into self-reinforcing mechanisms in the multi-stakeholder project's early stage, our findings also reveal how the structure of the stakeholder network contributed to path dependence processes during Phase I. According to our evidence, the stable and heterogeneous structure of the project stakeholder network constrained the project's 
conceptualization and scoping processes. The fragmented stakeholder ownership structure, which had developed slowly over decades, made it difficult to agree common project goals and design principles, and created inertia in the face of change. Stakeholder multiplicity - that is, diverse stakeholders with different goals (Oliver, 1991) — combined with fixed stakeholder positions and interests dominated early decision-making processes and direction setting. As a consequence, efforts to renew the city center and shape the project's design and scope were restricted by conflicting and fixed business logics because of the asymmetry of actors' interests.

\section{Path creation processes during the early stage of multi-stakeholder projects}

Our evidence reveals various indicators of path creation processes that align with Garud and Karnoe's (2001) findings and that increased towards the end of the Tapiola project's early stage. In combination with the unexpected rise of other competitive city districts, the initial decision to build the metro to Espoo in 2006 represented an exogenous shock to the Tapiola project, activating forces that eventually enabled the path to be broken and redirected. In addition, changes in the stakeholder network structure further facilitated path creation.

According to our findings, there was a transitional period between the metro decision and 2010, during which path dependence co-existed with path creation processes. During the transitional phase, there were indicators of inefficiencies, with equivocality and uncertainty among actors concerning appropriate methods and rules for planning the project's scope and the roles of the different stakeholders. During this phase, certain entrepreneurial actors, including the newly appointed project manager at City of Espoo and the new architect, were creating new future visions, planning rules, and guidelines for the project that deviated significantly from earlier planning principles. This created confusion and impeded planning, as some actors were still inclined, for example, to adhere to the central tower height limits. 
Our findings add to knowledge of how path creation processes manifest in the early stage of networked projects and how actors may create new relevance structures that guide the project onto a new path. In particular, our analysis suggests that the new individual actors (i.e., active agents) (Garud et al., 2010) joining the Tapiola project (such as the City of Espoo's entrepreneurial project director and the new architect) possessed an ability to discover that played an important role in the path creation processes that emerged and came to prominence from 2009 onward. The evidence suggests that these key entrepreneurial agents were able to mindfully create a new vision and plan for the project that deviated from expectations generally associated with Tapiola district and from the project's prior scope.

The strategic shaping activities identified in our case analysis seem central to these path creation processes. First, the key team, including the project director, city planning officials, and architects, engaged in entrepreneurial action by translating the concept and ideas into a more courageous initiative that increased the overall value creation potential of the multi-stakeholder project as a whole. The concept broke existing frames - violating, for instance, the low-rise building tendency characteristic of Tapiola while still retaining garden city elements. These new ideas and the architectural vision for the new center were persistently spread, shared, and circulated among the stakeholders, who gradually escaped their cognitive locks to engage in project planning with a wider scope.

As part of their boundary spanning activities, the core actors organized a range of engagement meetings with different stakeholders. The team also exhibited flexibility, incorporating additional elements in the plans that emerged through dialogue and interaction with the various stakeholders. In addition, they iteratively created a commercially viable plan for the project, to which stakeholders could link their business interests. This transformation was necessary in 
order to shape the preferences of stakeholders and to generate momentum for the new project vision. Despite resistance from the National Board of Antiquities and, the Tapiola Guild, the core stakeholders persisted in their efforts to renew Tapiola with the perseverance required for path creation (Garud and Karnoe, 2001). As a result, the resources of key stakeholders such as TRE were mobilized along with those of new stakeholders, and a powerful collective was formed of actors committed to taking the project forward with the new scope.

Based on our analysis, we argue that the wilful pushing at the boundaries in the renewal and construction of Tapiola's commercial center area is evidence of path creation. It is also our interpretation that these path creation processes eliminated many of the historical constraints on decision making, and the project entered a phase in which the goals, design solutions and scope of the project were reformulated and finally institutionalized. During this final phase, the activities of stakeholders were increasingly directed to strengthening the new path by linking new elements to the project's renewed concept and value constellation. In addition, attempts intensified to legitimize the project through public information sessions, dialogues, and reports. Our observations further suggest that the new direction accounts for the project's new identity as bold and courageous.

Our analysis also provides new evidence of how changes in the structure of the Tapiola project's stakeholder network (particularly in the positions and relationships of stakeholders) contributed to the grounding of a new path. During Phase II, TRE was able to increase its salience (Mitchell et al., 1997) in the stakeholder network, primarily through resource-based influencing strategies (Frooman, 1999). This strengthening of its position also legitimized its role and new identity as a leader in the Tapiola project. As a consequence of acquisitions made by TRE, the multiplicity of the network (Oliver, 1991) decreased, simplifying decision-making processes. Paralleling these 
developments, the City of Espoo adopted a proactive approach to the project, increasing its interaction with TRE. As a result, the relationship between these two stakeholders deepened, affording opportunities for more open dialogue around the project's scope and its value creation potential. Finally, the introduction and engagement of new stakeholders from outside the project was a significant factor, causing project stakeholders to question their earlier assumptions about the project's scope.

\section{DISCUSSION AND CONCLUSIONS}

Building on research on path dependence (Sydow et al., 2009), path creation (Garud and Karnoe, 2001) and stakeholder management, the present findings illustrate how a project's goals and overall scope evolve during the early stage of a multi-stakeholder project. The study makes a number of contributions to the literatures on the management of the project's early stage, project stakeholder management, and path dependence and path creation.

\section{Contributions to research on the management of the project's early stage}

These results suggest that a project's connection to its historical context may significantly narrow the available choices, value creation potential, and direction of a project. This finding challenges the widespread assumption of multiple choices and opportunities in a project's earliest stages (Morris and Hough, 1987; Floricel and Miller, 2001), pointing instead to the power and influence of historical forces and self-reinforcing mechanisms. While previous studies have commonly depicted the early phase of complex projects as entailing the widest range of design options (Kolltveit and Grønhaug, 2004), our findings demonstrate in detail how various self-reinforcing mechanisms may induce an early state of lock-in. This may explain why it is often difficult to achieve significant progress in large and complex projects, even when adequately resourced. These findings also provide critical knowledge of how, through different 
processes of path creation, the project's design and overall scope changed radically in a direction that deviated significantly from the original plans.

Overall, the findings offer contextualized and fine-grained knowledge of the dynamics of goal and scope formulation processes during the early stage of large and complex multi-actor projects, largely overlooked in previous project management research (Morris, 2013; Samset and Volden, 2015). Our findings on the evolving scope and direction of the project in a continuously changing multi-stakeholder context indicate the critical importance of moving beyond a linear approach to the project's early stage for a deeper understanding of successful management.

\section{Contributions to research on project stakeholder management}

In showing how the stakeholder network and changes in that network can contribute to processes of path dependence and path creation, the present study augments understanding of how the structure of multi-stakeholder networks can both constrain (Levering et al., 2013) and facilitate search and scoping processes during a project's early stage. In our case study, the historically fragmented ownership structure, and the fixed positions of stakeholders, in combination with shared and unquestioned assumptions underpinning the project's planning principles, were driving mechanisms for path dependence processes during the project's early stage. However, of particular interest is the evidence of how the emergent dynamics of the stakeholder networkreduced stakeholder multiplicity, the strengthening position of the key property owner, and more embedded relationships between key stakeholders - contributed to the creation of a new project path. This evolution was reinforced by an entrepreneurial project director, who activated path creation processes that enabled mindful deviation from the unquestioned historic ideals that had served as planning principles. Through idea translation and sharing and commitment building among stakeholders, the path of the project changed radically in a direction that deviated 
significantly from initial expectations. Subsequently, the activities of stakeholders focused on linking new elements to the renewed project concept and value constellation in order to strengthen the new path. Prior research has largely neglected this network perspective, instead considering project stakeholders primarily in terms of dyadic relationships (Aaltonen and Kujala, 2016; Achterkamp and Vos, 2008; Yang et al., 2009). In this way, our results provide new knowledge of how such network-related processes facilitate change in multi-stakeholder projects, and how the dominant coalition of key stakeholders that can shape the project's objectives and scope may actually emerge.

\section{Contributions to path dependence and path creation research}

While earlier research has focused primarily on path dependence within single organizations (Sydow et al., 2009), the present study represents a detailed empirical examination of temporary inter-organizational networks. With these new insights into how the mechanisms of path dependence actually operate at the level of inter-organizational projects and, in particular, how they can affect a multi-stakeholder project's overall goals and scoping process, we add to the limited knowledge of path dependence in projects and project-based firms (Manning and Sydow, 2011; Levering et al., 2013). Additionally, as research on path dependence and path creation has rarely been integrated with stakeholder theory (Lamberg et al., 2008), the study provides new and unique knowledge of how the dynamics of the initial stakeholder context affect goal formation processes in multi-stakeholder projects. Finally, our findings supplement the recent integration of research on path dependence and creation (Sydow et al., 2013), which have traditionally been investigated separately.

\section{Managerial implications}


The present study has five key implications for practitioners initiating and managing complex projects in urban contexts. First, because of historical events and norms among stakeholders in a given district, development projects may be locked into specific paths in their early stage, drastically limiting the number of options for developers. This finding contrasts with the traditional view of the project early stage as a "tabula rasa," where development ideas are constrained only by the developer's creativity and financial means. Second, this study characterizes the processes that may lock a project into a specific path, helping practitioners to assess whether or not they are facing a lock-in situation in projects they are initiating. Third, our observations of how stakeholders deconstruct a shared project path should support practitioners' efforts to break such paths when this is necessary in pursuing their objectives. In particular, identifying and leveraging exogenous shocks may be crucial in building commitment to new development ideas within the project network. Fourth, our findings highlight the central role of interaction within the project stakeholder network in path dependence and path creation processes, including both private and public actors. By their nature, these processes cannot be controlled by any single project actor; as they are emergent and involve multiple stakeholders, they are more negotiation-based than control-oriented. Finally, our observations highlight the central role of the project manager in driving deconstruction and redirection of the project path. In the present case, the project director acted as an entrepreneurial agent, continuously generating new ideas and negotiating with project stakeholders to build commitment. These results also highlight the importance of project managers' influencing tactics and political skills in managing the complex stakeholder environment (Bourne and Walker, 2005), as well as their abilities as an entrepreneur, which have been inadequately addressed in earlier studies.

\section{Areas for future research}


While existing research has discussed the processes of path dependence, there has been limited research on the contextual conditions that give rise to or support these processes - that is, the antecedents of path dependence. Therefore, further study of these antecedents in projects that may be locked into a specific path would be of great value. The observed phenomena involve multiple stakeholders and interrelated processes. As actors plan their future both independently and at a shared level involving multiple actors, both micro and macro perspectives in future studies would facilitate better understanding of how individual project network stakeholders interact in network-level processes. Following the PDCA cycle logic could support this analysis and also reveal the potential tensions that may arise between the PDCA planning cycle structure of project management and the political decision-making processes. Furthermore, as the processes of path dependence and path creation are highly time-dependent, the issue of timing is central to any empirical research on this topic. The project network of an urban renewal project in our study was undergoing a major transition and therefore offered a fruitful context for observing these phenomena. Further research in diverse urban contexts might usefully explore processes of path dependence and path creation under more stable conditions. Finally, while our informants included representatives of many stakeholders of the project network, further studies accessing all of the many stakeholders in urban development projects would enhance our understanding of micro and macro level processes and of their interaction. 


\section{REFERENCES}

Aaltonen, K., Kujala, J., Havela, L., Savage, G., 2015. Stakeholder dynamics during the project front-end: The case of nuclear waste repository projects. Project Management Journal, 46(6), 1541.

Aaltonen, K., Kujala, J., 2016. Towards an improved understanding of project stakeholder landscapes. International Journal of Project Management, 34(8), 1537-1552.

Achterkamp, M.C., Vos, J.F.J., 2008. Investigating the use of the stakeholder notion in project management literature, a meta-analysis. International Journal of Project Management, 26(7), 749-757.

Arthur, B.W., 1989. Competing technologies, increasing returns, and lock-in by historical events. Economic Journal, 99, 116-132.

Artto, K., Ahola, T., Vartiainen, V., 2016. From the front end of projects to the back end of operations: managing projects for value creation throughout the system lifecycle. International Journal of Project Management, 34(2), 258-270.

Artto, K., Kujala, J., Dietrich, P., Martinsuo, M., 2008. What is project strategy? International Journal of Project Management, 26(1), 4-12.

Bizzi, L., Langley, A., 2012. Studying processes in and around networks. Industrial Marketing Management, 41(2), 224-234.

Boland, R.J., Lyytinen, K., Yoo, Y., 2007. Wakes of innovation in project networks: The case of digital 3-D representations in architecture, engineering and construction. Organization Science, 18(4), 631-647.

Bourne, L., Walker, D.H.T., 2005. Visualizing and mapping stakeholder influence. Management Decision, 43(5), 649-660.

Brady, T., Davies, A., 2004. Building solution capabilities: From exploratory to exploitative learning. Organization Studies, 25(9), 1601-1621.

Brady, T., Davies, A., Gann, D., 2005. Can integrated solutions business models work in construction? Building Research \& Information, 33(6), 571-579.

Cova, B., Ghauri, P., Salle, R., 2002. Project Marketing: Beyond Competitive Bidding. John Wiley \& Sons, Chichester.

David, P., 1985. Clio and the economics of QWERTY. American Economic Review, 75, 332337.

DeFillippi, R., Sydow, J., 2016. Project networks: Governance choices and paradoxical tensions. Project Management Journal, 47(5), 6-17.

Edkins, A., Geraldi, J., Morris, P., Smith, A., 2013. Exploring the front-end of project management. Engineering Project Organization Journal, 3(2), 71-85.

Eisenhardt, K., 1989. Building theories from case study research. Academy of Management Review, 14(4), 532-550.

Floricel, S., Miller, R., 2001. Strategizing for anticipated risks and turbulence in large-scale engineering projects. International Journal of Project Management, 19(8), 445-455. 
Frooman, J., 1999. Stakeholder influence strategies. The Academy of Management Review, 24(2), 191-205.

Garud, R., Karnoe, P., 2001. Path creation as a process of mindful deviation, in: Garud, R., Karnoe, P. (Eds.), Path dependence and creation. Lawrence Erlbaum Associates, pp. 1-38.

Garud, R., Kumaraswamy, A., Karnoe, P., 2010. Path dependence or path creation? Journal of Management Studies, 47(4), 760-774.

Hellgren, B., Stjernberg, T., 1995. Design and implementation in major investments-A project network approach. Scandinavian Journal of Management, 11(4), 377-394.

Hellström, M., Ruuska, I., Wikström, K., Jåfs, D., 2013. Project governance and path creation in the early stages of Finnish nuclear power projects. International Journal of Project Management 31(5), 712-772.

Kolltveit, B.J., Grønhaug, K., 2004. The importance of the early phase: The case of construction and building projects. International Journal of Project Management 22(7), 545-551.

Lamberg, J-A., Pajunen, K., Parvinen, P., Savage, G., 2008. Stakeholder management and path dependence in organizational transitions. Management Decision, 46(6): 846-863.

Langley, A., 1999. Strategies for theorizing from process data. Academy of Management Review, 24(4), 691-710.

Levering, R., Ligthart, R., Noorderhaven, N., Oerlemans, L., 2013. Continuity and change in interorganizational project practices: The Dutch shipbuilding industry, 1950-2010. International Journal of Project Management, 31(5), 735-747.

Lundin, R.A., Söderholm, A., 1995. A theory of temporary organization. Scandinavian Journal of Management, 11(4), 437-455.

Manning, S., Sydow, J., 2011. Projects, paths, and practices: Sustaining and leveraging projectbased relationships. Industrial and Corporate Change, 20(5): 1369-1402.

Matinheikki, J., Artto, K., Peltokorpi, A., Rajala. R., 2016. Managing inter-organizational networks for value creation in the front-end of projects. International Journal of Project Management, 34(7), 1226-1241.

Miller, R., Lessard, D., 2000. The Strategic Management of Large Engineering Projects: Shaping Institutions, Risks and Governance. MIT Press, Cambridge, MA.

Mitchell, R.K., Agle, B.R., Wood, D.J., 1997. Toward a theory of stakeholder identification and salience: Defining the principle of who and what really counts. Academy of Management Review 22(4), 853-886.

Morris, P.W.G., Hough, G.H., 1987. The Anatomy of Major Projects-A Study of the Reality of Project Management. John Wiley \& Sons, Chichester.

Oliver C., 1991. Strategic responses to institutional processes. Academy of Management Review, 16(1), 145-179.

Pierson, P., 2000. Increasing returns, path dependence, and the study of politics. American Political Science Review, 94, 251-267. 
Shane, S., Venkataraman, S., 2000. The promise of entrepreneurship as a field of research. Academy of Management Review, 25(1), 217-226.

Söderlund, J., 2004. On the broadening scope of the research on projects: a review and a model for analysis. International Journal of Project Management, 22(8), 655-667.

Sydow, J., Schreyögg, G., Koch, J., 2009. Organizational path dependence: Opening the black box. Academy of Management Review, 34(4), 689-709.

Sydow, J., Windeler, A., Müller-Seitz, G., Langer, K., 2013. Path constitution analysis: A methodology for understanding path dependence and path creation. BuR Business Research Journal, 5(2), 155-176.

Vergne, J-P., Durand, R., 2010. The missing link between the theory and empirics of path dependence: conceptual clarification, testability issue, and methodological implications. Journal of Management Studies, 47(4), 736-759.

Yin, R., 2009. Case Study Research: Design and Methods, revised ed. Sage Publications, Thousand Oaks, CA. 


\section{Appendix 1.}

Key stakeholders of the Tapiola project's early stage (2000-2012)

Name

LocalTapiola Real Estate Asset Management Ltd

(TRE)

HKP Architects

SARC Architects

Wereldhave

Stockmann

Tapiola Guild Association

Western metro

City of Espoo

National Board of

Antiquities

City Planning Committee

\section{Description}

A large real estate investment and development firm with a strong presence in Tapiola district

A design and architect company

An architect company widely known for its many recognized designs

A major property owner in Tapiola

Leading department store chain in Finland with strong presence in Tapiola district

Organization for the purpose of promoting the interests of residents of Tapiola district

Organization set up for the purpose of building and operating a metro line (with one of the stations situated in Tapiola)

Tapiola district is situated within the City of Espoo

A government authority set up for the preservation of historical heritage.

Responsible for evaluating and approving city plans 